Dokuz Eylül Üniversitesi-Mühendislik Fakültesi

Fen ve Mühendislik Dergisi

Cilt 19, Sayı 56, Mayıs 2017
Dokuz Eylul University-Faculty of Engineering Journal of Science and Engineering Volume 19, Issue 56, May 2017

DOI: $10.21205 /$ deufmd.2017195642

\title{
Deri Sanayinde İhracatı Tehdit Eden Yasaklı Maddelerin Ayakkabılık Mamul Derilerde Araştırılması
}

\author{
Ersin ÖNEM"1, Hüseyin Ata KARAVANA', Ali YORGANCIOĞLU¹, Bahri BAŞARAN
}

1Ege Üniversitesi, Mühendislik Fakültesi, Deri Mühendisliği Bölümü, 35100, İzmir

(Alınıș / Received: 27.10.2016, Kabul / Accepted: 28.01.2017, Online Yayınlanma / Published Online: 02.05.2017)

Anahtar Kelimeler Deri sanayi,

İhracat, Yasaklı maddeler,

Çevre, İnsan sağlığı
Özet: Deri sanayi büyük ölçüde ihracata yönelik olarak faaliyet göstermektedir. Günümüzde deri sektöründe artan rekabet koşulları kalite kriterlerinin değişmesine neden olmuştur. Çevre bilincinin ve insan sağlı̆̆ına verilen değerin artmasıyla deri işlemede kullanılan zararlı kimyasalların kullanımı kaldırılmakta, yahut sınırlandırılmaktadır. Bu çalışmada, toksik etkisi olan ve deri ürünlerinde bulunması istenmeyen ya da belli sınırlandırmaları olan bazı bileșenler üzerinde durulmuștur. Bu amaçla mamul hale gelmiș ayakkabılık derilerde azo boyarmadde, fitalat, formaldehit, krom(VI), alkil fenol etoksilat (APEO), nonil fenol etoksilat (NPEO) ve kısa zincirli klorlanmış parafin (SCCP) analizleri gerçekleștirilmiş ve ayakkabılık derilerdeki içerikleri araştırılmıștır. Sonuçlar ayakkabılık derilerin azo boyarmadde, krom(VI) ve NPEO içeriklerinin sırasıyla 35 ppm, 5.4 ppm ve 1520 ppm değerleri ile tanımlanan limit değerlerin üzerinde olduğunu göstermiştir.

\section{Investigation of the Restricted Substances Threaten to Exports in Finished Upper Leather Products}

\begin{abstract}
Keywords Leather industry, Exports, Restricted substances, Environment, Human health

Abstract: Leather industry widely trades intended to exports. Nowadays, increasing competition conditions in the sector caused to change the quality criterias. Use of the hazardous chemicals in leather processing is removed or restricted with the inreased environmental conscious and increased conscious for the human health. In this study, it was put emphasis on the some substances having toxic effect and undesirable or restricted ones in terms of the leather products. In this context, analyses of azo dye, phthalate, formaldehyde, chromium(VI), alkylphenol ethoxylate (APEO), nonylphenol ethoxylate (NPEO) and short chain chlorinated paraffin (SCCP) in finished upper leathers were carried out and restricted substances were investigated. Results showed that azo dye, chromium(VI) and NPEO contents of the upper leathers were higher than the described limit values with $35 \mathrm{ppm}, 5.4 \mathrm{ppm}$ and $1520 \mathrm{ppm}$, respectively.
\end{abstract}

*Sorumlu yazar: bahri.basaran@gmail.com 


\section{Giriş}

Dünyada imalat sanayi alt sektörlerinde küreselleşmenin etkisiyle hem sektörler arasında hem de ülkeler arasında önemli yapılanmalar ve dönüşümler ortaya çımaktadır. Türkiye'de ise gelirde artış, tüketim kalıplarındaki değişme, Avrupa Birliği (AB) ile gümrük birliği sonrasında artan diş rekabet, ihracata ağırlık verilmesi gibi dinamikler sektörlerin gelişme eğilimleri üzerinde ve yapılanmasında etkili olmuştur. Böyle bir ortamda, sektörlerle ilgili tüm kesimler için mevcut durumun tespiti ve değerlendirilmesi konuları oldukça önem arz etmektedir.

Deri ve deri ürünleri sanayi, son 30 yılda dünyada ve Türkiye'de dinamik bir süreç içine girmiştir. Sektör, hem ülkemiz ekonomisi hem de dünya deri ve deri ürünleri sanayi içinde çoğu zaman önemsenecek bir yere sahip olmuştur. Özellikle Rusya'nın her kalitedeki deri ürünlerine olan yüksek talebi ve büyük kâr marjı ülkeye önemli döviz girdileri sağlamıştır.

Deri sektöründe yıllar geçtikçe çevre ve insan sağlığını etkileyen bileşenler üzerine sürekli olarak sınırlandırmalar yahut yasaklamalar getirilmiştir. Bunun sonucunda ihracatta dikkat edilmesi gereken birçok parametre ortaya çıkmıştır. Uluslararası yönetmeliklere uygun üretim yapamayan firmalar ihracatta önemli sıkıntılar yaşar duruma gelmiştir.

Ülkemizde çoğu diğer sektörün ihracatlarında hızlı artış devam etmektedir. Buna karşın, ülkemiz deri ve deri ürünleri ihracat artışının daha düşük hızda olması ve başta Çin olmak üzere diğer rakip ülkelerden ithalatın hızla artması sektörde rekabet gücünün ve ihraç ürünlerinin sorgulanmasını gerekli hale getirmiştir [1]. Bu çalışmada, son yıllarda özellikle ayakkabı sektöründe ihracatı önemli derecede etkileyen yasaklı bileşenler üzerinde durulmuş ve İzmir'deki firmalar tarafından üretilen ayakkabılık mamul deri ürünlerindeki içerikler araștırılmıștır. Özellikle son yıllarda gündeme gelen bu hususlar deri sanayi ihraç ürünlerinin kalite özelliklerinin belirlenmesinde anahtar rol oynamaktadır.

\section{Deri Materyallerinde Toksik Etkisi Olan ve Tespit Edilmesi Gereken Kimyasallar}

Deri endüstrisinde ham derinin mamul deriye dönüştürülmesi sırasında pek çok sayıda doğal ve sentetik kimyasal kullanılmaktadır. 20. yüzyılda kimya sanayindeki teknolojik gelișmeler ile deri üretimi sırasında kullanılan ürün yelpazesi genişlemiş ve kimyasallara kazandırılan birçok yeni özellik sayesinde tüketici beklentilerini daha çok karşılayan deriler üretilmeye başlanmıștır. Üretim sırasında istenilen özelliklerin sağlanması amacıyla birçok basamaktan geçen deri ürünleri, işlem gördüğü her basamakta belirli miktarda kimyasallar ile muamele edilmektedir. Tüm bu teknolojik gelişmeler sayesinde dayanıklılıkları, su itici özellikleri, yanmazlıkları ve daha birçok özelliği güçlü olan derilere; renk seçeneği kısıtlı ve boyaması zor olan doğal boyama yöntemleri yerini milyonlarca renk seçeneği olan kısa sürede boyanabilen giysi seçeneklerine bırakmıștır. Tüm bu olumlu etkilerinin yanında, kimyasal ürünler, her geçen gün yeni sorunlara yol açmıştır. Sürekli olarak ortaya çıkan yeni ürünlerin bazılarının ve bunların atıklarının insan sağlığı ve çevre üzerine olumsuz etkileri ortaya çlkmaya başlamıştır [2]. Kimyasalların insan sağlığı ve çevre üzerinde yaratabileceği olumsuz etkilerine karşı koruma sağlamak amacıyla toksik ve tehlikeli özellikleri ile ilgili düzenlemeler ve kısıtlamalar yapılmaktadır. Son yıllarda deri endüstrisinde kısıtlanmıș maddelere olan farkındalık çok daha önemli hale gelmiştir. Deri üretim sektöründeki 
gelişmeler ile birlikte yapılan araştırmalarda deri mamullerindeki insan sağlığını ve çevreyi tehdit eden unsurlar belirlenmiş ve bazı düzenlemeler ile birçok kimyasal ürüne kısıtlamalar getirilmiş ya da yasaklanmıştır [1].

Gelișmiş ülkelerde, çevreye zarar verebilecek tehlikeli maddelerin çevresel risklerini değerlendirebilmek için çeşitli çalışmalar yapılmakta, modeller geliştirilmekte, veri bankaları kurulmakta ve acil eylem planları oluşturulmaktadır. Maddelerin ve Karışımların Sinıflandırılması, Etiketlenmesi ve Ambalajlanmasına ilişkin EC/1272/2008 sayılı CLP Tüzüğü Avrupa Parlementosu ve Konseyi Kararı 30 Aralık 2008 tarihinde yayımlanmış ve 20 Ocak 2009 tarihinde yürürlüğe girmiştir. İnsan sağlığının ve çevrenin kimyasalların etkilerinden en üst düzeyde korunması, kimyasallarla ilgili risk yönetiminden üreticilerin ve ithalatçıların sorumlu kılınması, tehlikelerin değerlendirilmesinde seçimli yöntemlerin özendirilmesi gibi amaçlarla "Kimyasalların Tescillendirilmesi, Değerlendirilmesi, Ruhsatlandırılması ve Kısıtlanması (REACH) düzenlemeleri yapılmıştır. REACH, üretim sürecinde kullandığı çok çeşitli kimyasal maddeler nedeniyle, deri ve deri ürünleri sanayini yakından ilgilendirmektedir. Deri materyallerinde toksik etkisi olan ve tespit edilmesi gereken kimyasallar için Avrupa ülkelerinde olduğu gibi Türkiye de Avrupa Birliği direktiflerine ve REACH tüzüğüne uygun hareket etmektedir. Yapılan düzenlemelerle birlikte nihai tüketicinin kullanımına yönelik ayakkabı, çanta ve eldiven gibi deri ürünlerinde bazı tehlikeli kimyasal maddelerin miktarlarında sinırlamalar ve yasaklamalar yapılmıştır [3].

\subsection{Azo boyarmaddeler}

Bu organik kimyasallar en çok üretilen ve kullanılan boyarmadde grubu olmakla birlikte bu grup içeresindeki bazı boyarmaddelerin insan sağlığına toksik etkisi bulunmaktadır [4]. Toksik etkili boyarmadde ile üretilen ürünler kullanan kişilerde cilt ile giysiler arasındaki etkileşim sonucu vücuttaki bakteriler, ter ve isı ile birlikte bu boyarmaddeleri kanserojen aril aminlere dönüştürmektedir.

Yasaklı azo boyarmaddelere ait ilk kısıtlamalar 1970'lerde Almanya'da başlamıştır. Daha sonra 1994 yılında ise ithalatına ve satışına yasak getirilmiştir. Almanya'nın başlatmış olduğu bu çalışmalar ile tüm Avrupa Birliği ülkelerinde 76/769/EEC direktifi ile belirlenmiş 22 adet aril amin grubundan oluşan azo boyarmaddeler ile boyanan ürünler üzerindeki maksimum konsantrasyon 30 ppm olarak belirlenmiştir. Deri ürünlerindeki azo boyarmaddelerden kaynaklı sorunların ortadan kaldırılması için araştırmacılar deri boyama işleminde doğal boyarmaddelerden faydalanılması gerektiğini belirtmişlerdir [5-7]. Ayrıca atık sulardaki azo boyarmaddelerin parçalanması için biyolojik yöntemlerden ve enzimlerden faydalanılmıştır $[8,9]$.

\subsection{Fitalatlar}

Kullanıldığı malzemelere esneklik, elastikiyet ve dayanıklılı özelliği katan fitalatlar; deri finisaj malzemeleri içerisinde fleksibiliteyi artırmak için kullanılan kimyasallardır. Bulundukları ortamdan buharlaşma, ter, yağ, tükürük ve isı ile serbest kalan fitalatlar solunan hava ile ve deri yolu ile kullanıcısı tarafından absorbe edilmektedir. Laboratuvar hayvanları üzerinde yapılan çalışmalar ile fitalatların hayvanlarda akciğer, karaciğer ve böbrek başta olmak üzere, özellikle de üreme sistemleri üzerinde karsinojen ve toksik etkileri tespit edilmiştir [10]. 
Fitalatların toksik etkileri sonucunda giysi materyalinde kullanımlarına kısıtlamalar getirilmiștir. Oyuncak ve çocuk bakım ürünlerinde bulunan fitalatlar ile başlayan kısıtlamalar tekstil sektörünü de kapsayacak şekilde genişletilmiştir. 2005 yılında Avrupa Birliği tarafından yayınlanan 2005/84/EC no'lu direktifi ile sinırlama getirilen yasaklı fitalatlar 6 (altı) adettir. REACH tüzüğü de kimya sanayisinde çok kullanılan bu 6 tane fitalat'ın nihai ürünler içerisindeki miktarlarında kısıtlamalar getirmiștir.

PVC ürünlerde boya, polimer ve diğer katkı maddelerine kıyasla ağırlıkça en fazla yüzde fitalatlara ait olup, en çok kullanılan fitalat DEHP'dir. DEHP'den sonra en yaygın üretime sahip diğer fitalatlar DIDP ve DINP'dir. 2005/84/ EC nolu Avrupa Birliği direktifine göre bu fitalatlar ile ilgili olarak deri ile yakın temas halinde olan ürünlerde ve oyuncak, çocuk bakım ürünlerinde olması gereken maksimum limit 1000 ppm olarak belirlenmiştir. Deri ürünlerinde fitalat sorununun çözümüne yönelik henüz yapılan güncel bir araștırma bulunmamaktadır.

\subsection{Krom (VI)}

Deriye olumlu özellikler kazandırması açısından günümüzde üretilen deri ürünlerinin yaklaşı \%85-90'ı üc değerlikli (Cr) tuzları ile tabaklanmaktadır [11]. $\mathrm{Cr}(\mathrm{VI})$ deri üretimi sırasında direkt olarak kullanılmasa da ısı, ışık ve nem gibi çeşitli çevre koşullarının etkisiyle deri ürünlerinin zamanla yașlanması sonucu, derideki Cr(III) yükseltgenerek Cr(VI)'ya dönüşebilmektedir. Sicaklık ve UV ıșınlarının etkisi sonucu olușan bozulma sırasında yağlama maddeleri, tabaklama maddeleri ve yardımc maddeler deri yapısına ait moleküller ile yer değiştirmekte ve serbest radikaller olușmaktadır. Olușan bu radikaller sonucu $\mathrm{Cr}(\mathrm{III}) \quad \mathrm{Cr}(\mathrm{VI}){ }^{\prime y}$ ya yükseltgenmektedir [12]. Deride Cr(VI) oluşumunun önlenmesi için son yıllarda birçok araştırma yapılmış ve üretimde özellikle bitkisel tanenlerden, antioksidan maddelerden ve nanopartiküllerden faydalanılmıștır [1215]. Deri mamullerinde bulunabilecek maksimum $\mathrm{Cr}(\mathrm{VI})$ miktarı için çeşitli ülkeler farklı sınır değerler belirlemişlerdir. Çizelge 1'de bazı standartlara ait $\mathrm{Cr}(\mathrm{VI})$ sinırlamaları görülmektedir. İhracatta yaşanan sıkıntılardan sonra Türkiye'deki çogu önemli firma şu anda Öko-Tex standardını uygulamaktadır.

\begin{tabular}{lll} 
Tablo 1. Cr(VI) sinırlamaları & \\
\hline Standart & Uygulama & Sınır Değer \\
\hline $\begin{array}{l}\text { Draft of European } \\
\text { Eco-Label }\end{array}$ & Ayakkabılık & $5 \mathrm{mg} / \mathrm{kg}$ \\
\hline $\begin{array}{l}\text { Toxproof (TÜV- } \\
\text { Rheinland) Label }\end{array}$ & $\begin{array}{l}\text { Tekstil, } \\
\text { ayakkabılık }\end{array}$ & Bulunmamalı \\
\hline Öko-Tex 100 Label & Tekstil, deri & Bulunmamalı \\
\hline SG Label & $\begin{array}{l}\text { Deri, tekstil, } \\
\text { kağıt, ahşap }\end{array}$ & Bulunmamalı \\
\hline LGR Label & Deri & Bulunmamalı \\
\hline
\end{tabular}

\subsection{Formaldehit}

Derilerdeki formaldehit içeriği günümüzde üzerinde önemle durulan ve mamul ürünlerde analizi istenen zararlı kimyasal maddelerin başında gelmektedir. Formaldehit; Avrupa Birliği tarafından insanlar için muhtemel kanserojen maddeler sinıfi olarak tanımlanan Kategori 3 listesine eklenmiştir. Derilerde bu gibi zararlı içeriklerin oluşumu, vücut ile direkt olarak temas eden ya da etmeyen tüm deri ürünlerinin insan sağlığını ciddi derecede etkilemesine neden olmaktadır. Şiddetli ağrı, istifrağ, koma ve ölüm büyük miktarlarda formaldehit yutulması veya solunması sonucu meydana gelebilmektedir.

Deri üretiminde formaldehit direkt olarak kullanılmamakla birlikte, deri sanayinde sıklıkla kullanılan üre formaldehit reçine, fenolik reçine, melamin reçine, beyaz sentetik tanenlerin üretiminde ve kondenzasyonunda formaldehitten 
$\begin{array}{lcr}\text { yararlanılması } & \text { mamul } & \text { derinin } \\ \text { formaldehit } & \text { içermesine } & \text { sebep }\end{array}$ olmaktadır. Formaldehit ile reaktifin reaksiyonunun hızlı ve ılımlı olması, bu şekilde üretilen ürünlerin üretim tekniklerinin basit ve ucuz olması, pek çok sanayi dalında olduğu gibi deri kimyasallarının üretiminde de tercih sebebidir. Deri ürünlerinde formaldehit oluşumunun önlenmesi için güncel birçok çalışma gerçekleştirilmiş, bu amaçla fenolik bileşenlerden ve antioksidan maddelerden yararlanılmıștır [13,14,16]. Çizelge 2'de deride formaldehit içeriği ile ilgili sinırlamalar verilmiştir.

Tablo 2. Deride formaldehit sınırlamaları

\begin{tabular}{|c|c|c|}
\hline \multicolumn{3}{|c|}{ Formaldehit Sınırlamaları } \\
\hline Standart & Uygulama & Sınır Değer \\
\hline Öko-Tex 100 Label & Ayakkabılık & $<75 \mathrm{ppm}$ \\
\hline $\begin{array}{ll}\text { Pirmasens } & \text { Ayakkabı } \\
\text { Enstitüsü } & \end{array}$ & Ayakkabılık & $<75 \mathrm{ppm}$ \\
\hline SG Label & Ayakkabılık & $<75 \mathrm{ppm}$ \\
\hline SG Label & Çocuk Ayakkabılık & $<50 \mathrm{ppm}$ \\
\hline
\end{tabular}

\subsection{Alkil fenoller}

Alkil fenoller (AP), fenollerin alkillenmesi ile elde edilen organik bileșiklerdir. Alkil fenol etoksilatlar (APEOs), dallanmış zincir içeren alkil fenolün etilen oksit ile reaksiyona girmesiyle oluşan yüzey aktif maddelerdir. Yaygın kullanılanlar APEO; Nonilfenoller

Nonilfenoletoksilatlar (NPEO), Oktilfenoller (OP), Oktilfenoletoksilatlar (OPEO)'dir.

Alkil fenol etoksilatlar (APEOs) noniyonik sürfaktanlarda kullanılan (yıllık 60.000 ton) bir sinıftır. Nonil fenol etoksilatlar da toplam üretilen APEOs'in hacim olarak \%80'ini oluşturmakta ve 50 yılı aşkın süredir önemli yüzey aktif maddeler olarak sanayide yaygın şekilde kullanılmaktadır. Bazı boyarmadde ve pigmentlerde de islaticı madde ve emülgatör olarak az miktarlarda kullanılmaktadır. APEOs'in biyolojik parçalanabilirliği düşük olduğu için son yıllarda temizlik ürünlerindeki kullanımı
Avrupa ülkelerinde kısıtlanmıştır [17].

Deri işlentisinde; islatma-yumuşatma, yağ giderme, finisaj işlemlerinde kullanılabilmektedir. Almanya'da 1998'den beri deterjanlarda APEO kullanımı yasaktır. EU directive 2003/53/EG, 2005 ocak ayı itibariyle formülasyonlarda 1000 ppm'den fazla NPEO kullanımını yasaklamıștır. 2020 yılına kadar Kuzeydoğu Atlantik'teki deniz çevresini etkileyen her türlü kimyasal madde atığını, emisyonunu ve kaybını sonlandırma amacı taşıyan OSPAR Ortak Prosedürü'nü hayata geçirmek için öncelikli olarak engellenmesi gereken kimyasal maddeler listesine nonil fenol ve nonil fenol etoksilatlar dahil edilmiştir. Avrupa Birliği içerisinde 2005 yılı Ocak ayı itibariyle kapalı çevrim sistemlerinden kaynaklı bazı küçük istisnalar dışında, $\% 0,1$ 'den yüksek oranda nonil fenol veya nonil fenol etoksilatlar içeren ürünler pazarda yer alamamaktadır. Yine yakın zamanda Çin'de ithalat ve ihracatı yasak olan zararlı kimyasallar listesine nonil fenol ve nonil fenol etoksilatlar dahil edilmiştir. Ancak bugüne kadar deri ürünlerinde alkil fenol ve nonil fenol etoksilat sorunlarının çözümüne yönelik yapılan önemli bir araştırma bulunmamaktadır.

\subsection{Kısa zincirli klorlanmış parafinler (SCCP)}

Kısa zincirli klorlanmış parafinler, zincir uzunluğu C10-C13 arasında değișen klorlanmış hidrokarbonlardır (Şekil 1).

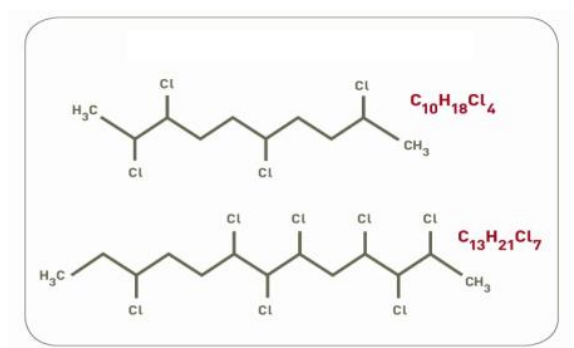

Şekil 1. Kısa zincirli klorlanmış parafin

SSCP'lerin ana kaynağı yağlama maddeleri ve finisaj aşamasında 
kullanılan bazı yağlar olabilmektedir. $\mathrm{Bu}$ bileşiklerin endüstriyel olarak kullanımı her ne kadar arzu edilse de, bileşikler doğaya salındığında giderilmesi bir o kadar zorlu olmaktadır. Klorlu parafinlerin zehirlilik derecesi klorlanma ve karbon zincir uzunluklarına göre değișiklik göstermektedir. Bu bileşiklerin düşük akut toksisiteleri olmasına rağmen, su ortamında göstermiş olduğu uzun süren etkilerinden dolayı çok toksik olarak sınıflandırılmaktadır [18]. Avrupa ülkelerinde uzun yıllardır klorlu parafinlere daha az odaklanılmasına rağmen günümüzde bu bileşiklere verilen önem artmaktadır. Bu durum bilhassa kısa zincirli klorlu parafinler (SCCP) için geçerlidir. Kısa zincirli klorlu parafinler Avrupa Birliği tarafından tehlikeli maddelerin kisıtlanmasina ilişkin ROHS direktifi'ne göre yüksek öncelikli zararlı madde olarak ve REACH regülasyonunda yüksek önem arz eden madde (SVHC) olarak tanımlanmıştır. 2001 yllında Avrupa Birliği kısa zincirli CP'leri öncelikli tehlikeli madde olarak listelemiştir. 2008 yllında ise SSCP'ler Yüksek Önem Arz Eden Maddeler listesine alınmıștır. Deri ürünlerinde kısa zincirli klorlu parafinlerin tespit edimesine yönelik literatürde yalnızca bir araştırma bulunmaktadır [19].

\section{Materyal ve Metot}

Deri materyali olarak; krom tabaklanmış ve ayakkabilık olarak mamul hale getirilmiş yerli dana derileri üzerinde çalışılmıştır. Deriler İzmir'de ayakkabılık üretim yapan firmalardan temin edilmiştir. Yasaklı içerikler olarak azo boyarmadde tayini TS EN ISO 17234-1 [20], fitalat tayini TS EN 14372 [21], kısa zincirli klorlanmış parafin ve alkil fenollerin tayini Kazlıçeşme Ar-Ge Merkezi ve Test Laboratuvarlarına ait kurum içi metot, formaldehit tayini TS EN ISO 17226-1 [22], krom(VI) tayini ise TS EN ISO 17075 standart test metoduna göre yapılmıștır [23]. Yapılan kimyasal analizler için mamul derilerden örnek alma Şekil 2'de gri renk ile gösterilen küçük kareli bölgeden gerçekleştirilmiştir.

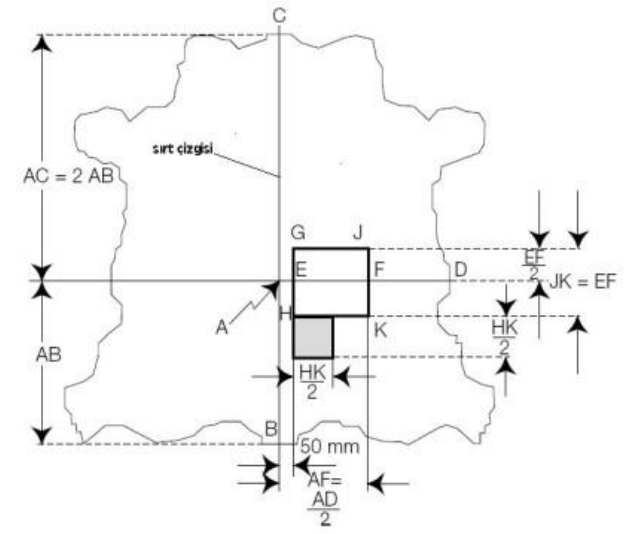

Şekil 2. Kimyasal analizler için örnek alma bölgesi

\section{Bulgular}

Türkiye'de deri sektörü yüksek ihracat potansiyeli ile ülke ekonomisi açısından önemli bir yere sahiptir. Türkiye'nin 10 . büyük sanayi kolu olarak yerini almaktadır. Emek yoğun bir üretim şekline sahip olması nedeniyle de geniş bir istihdam yaratma kapasitesine sahiptir. Günümüzde artan çevre bilinci deri üretimini ve üretimde kullanılan kimyasalların sorgulanmasını ve araștırılmasını gerekli hale getirmiştir. Özellikle mamul hale gelmiş deri ürünlerinin eko etiket taşıması artan rekabet koşullarında ihracatı etkileyen en önemli unsurlardan biri olmuștur. $\mathrm{Bu}$ bağlamda kimyasalların tehlikelerinden kaynaklanan sağlık sorunlarının ve çevre kirliliğinin giderilmesi için çevre dostu üretim, çevre koruma, sağlık açısından risk oluşturabilecek kimyasalların kullanımının azaltılması/engellenmesi gerekmektedir. Alternatif yöntemlerin kullanılması ve ürün güvenliği sağlanması ile kimyasalların insan sağlığı ve çevre üzerindeki olumsuz etkileri en aza indirilmelidir.

Son yıllarda ekolojik ürünlere olan talep ve bu doğrultuda getirilen yönetmelikler 
deri sanayi ihraç ürünlerinde birçok kimyasal bileşenin araştırılmasını zorunlu hale getirmiştir. Özellikle ayakkabılık deri ürünleri ve ayakkabılar

ile ilgili son zamanlarda basında da önemli haberler yer almıștır. Firmalar ürettikleri deriler veya ürettikleri ayakkabılarda belirli testleri yaptırmak ve ürünlerinin insan sağlığına zararlı herhangi bir bileșen içermediğine dair analiz raporlarını edinmek zorunda kalmıştır. Belirli testlerden geçemeyen firmalar gerek yurtiçi piyasada gerekse ihracatta çok ciddi problemlerle karşı karşıya kalmıştır. $\mathrm{Bu}$ nedenle araştırmamızda özellikle ayakkabılık deri ürünlerindeki yasaklı bileșenler üzerinde durulmuştur. Çizelge 3'de yasaklı içeriklere ilişkin limit değerler [24] ve ayakkabılık deriler üzerinde yaptığımız analizler sonucunda tespit edilen ortalama değerler verilmiştir.

Tablo 3. Ayakkabılık derilerde tespit edilen değerler

\begin{tabular}{|l|l|l|l|}
\hline $\begin{array}{l}\text { Yasaklı } \\
\text { içerikler }\end{array}$ & Limit değerler & Yönetmelik & $\begin{array}{l}\text { Tespit edilen } \\
\text { değerler }\end{array}$ \\
\hline $\begin{array}{l}\text { Azo } \\
\text { boyarmadde }\end{array}$ & $30 \mathrm{ppm}$ & EU directive 76/769/EEC & $35 \mathrm{ppm}$ \\
\hline Krom (VI) & $0-5 \mathrm{ppm}$ & European Eco-Label (4/8/97) & $5.4 \mathrm{ppm}$ \\
\hline Apeo & $1000 \mathrm{ppm}$ & EU directive 2003/53/EG & $<50 \mathrm{ppm}$ \\
\hline Npeo & $1000 \mathrm{ppm}$ & EU directive 2003/53/EG & $1520 \mathrm{ppm}$ \\
\hline Fitalat & $1000 \mathrm{ppm}$ & EU directive 2005/84/EC & $\begin{array}{l}\text { Tespit } \\
\text { edilmedi }\end{array}$ \\
\hline Formaldehit & $\begin{array}{l}\text { Yetişkin ürünlerinde: } 75 \\
\text { ppm } \\
\text { Çocuk ürünlerinde: } 50 \mathrm{ppm}\end{array}$ & $\begin{array}{l}\text { Öko-Tex 100 Label } \\
\text { SG Label }\end{array}$ & $20 \mathrm{ppm}$ \\
\hline SCCP & 1000 ppm & $\begin{array}{l}\text { EU POP Regulation EC } \\
850 / 2004\end{array}$ & $340 \mathrm{ppm}$ \\
\hline
\end{tabular}

Çizelge $\quad 3 \quad$ incelendiğinde; gerçekleştirilen analiz sonuçlarına göre üretilen ayakkabılık derilerin azo boyarmadde, krom(VI) ve NPEO içeriklerinin uluslararası tanımlanan limit değerlerin üzerinde olduğu, çevre ve insan sağlığı açısından bir risk oluşturabileceği görülmektedir. Tespit edilen değerlere göre bu derilerin ihracatında sıkıntı yaşanabileceği ve eko etiket alma konusunda zorluklarla karşılaşılacağı anlaşılmaktadır. Bu derilerin yurtiçi ve yurtdışı piyasalarında satışı için gerekli önlemlerin alınması gerekmektedir. $\mathrm{Bu}$ şekilde üretilen derilerin ülke ekonomisine tekrar kazandırılabilmesi için sonuç odaklı çözüm önerileri geliştirilmesi kaçınılmazdır. Deriye olumlu özellikler kazandırması açısından üretimde kullanılması kaçınılmaz olan ürünlerin mamul ürünlerde açı̆̆a çıkması bir şekilde elimine edilerek olumsuz özellikleri giderilmelidir.

\section{Tartışma ve Sonuç}

Üretiminde kullanılarak ihracatta sıkıntı yaşanan derilerdeki azo boyarmadde içeriğinin elimine edilmesi için ağartma işlemi yapılarak azo boyarmaddeler deriden sökülebilir ve boyama işlemi tekrardan yapılabilir. Aksi halde firmalar dıș piyasaya satamadıkları ürünler nedeniyle büyük zarara uğrayabilir, hatta iflas edebilir. Yapılan bir araştırmada hidrojen peroksit vasitasıyla azo boyarmaddelerin parçalanması başarıyla gerçekleştirilmiştir [25]. 
Deri ürünlerinde $\mathrm{Cr}(\mathrm{VI})$ oluşumu ise yıllardır üzerinde durulan ve aşılması gereken önemli problemlerin bașında gelmektedir. $\mathrm{Bu}$ gibi ağır metallerin oluşumu insan vücudu ile direkt temas eden giysilik, mobilyalık, ayakkabılık gibi deri ürünlerinin insan sağlığını ciddi derecede etkilemesine neden olmaktadır [26,27]. Son yıllarda Cr(VI) oluşumunun engellenmesi üzerine çeşitli çalışmalar yapılmış ve çözüm önerileri getirilmiştir. Araştırmacılar antioksidan özelliğe sahip bitki ekstraktlarının $\mathrm{Cr}(\mathrm{VI})$ oluşumunu önlediğini bildirmişlerdir. Kullanılan bitki ekstraktları ile derilerdeki krom (VI) miktarı 24 ppm'lerden 33 ppm'lere düşürülmüștür [12]. Yine valeks ve kına ekstraktlarının $\mathrm{Cr}(\mathrm{VI})$ oluşumunun önlenmesinde güçlü antioksidan fenolik maddeler oldugu bildirilmiștir [14]. Bir başka çalışmada deri üretiminin finisaj aşamasında nano ZnO kullanımının $\mathrm{Cr}(\mathrm{VI})$ oluşumunu neredeyse sıfıra indirdiğ $\mathrm{bildirilmiştir.} \mathrm{ZnO}$ nanopartikülleri ile giysilik mamul koyun derilerindeki mevcut $\mathrm{Cr}(\mathrm{VI})$ miktarı 3 ppm'in altına inmiştir [15]. Ayrica antioksidan bir madde olarak tannik asit kullanımı ile deride Cr(VI) oluşumu önemli ölçüde giderilmiş kontrol örneklerindeki mevcut Cr(VI) değeri 50 ppm'lerden 5 ppm düzeyine düşürülmüştür [13].

Getirilen kisitlamalardan dolayı üretimde kullanılan alkil fenoller yerine alternatif yüzey aktif maddelerin kullanılması önerilmektedir. Suda çözülme özelliğine sahip olmayan NP ve OP ise deri sanayinde kullanılmamaktadır. Gelişen teknoloji ile zararl fitalatlar yerine alternatifleri olan toksik etkisi olmayan kimyasallar ve PVC yerine polietilen, polipropilen plastikler tercih edilmeli, PVC materyaller kullanılacak ise ısıdan ve uzun süreli kullanımdan kaçınılmalıdır.
Formaldehit oluşumuna sebep olan deriye dolgunluk veren sintanlar ve reçineler, mamul deriden beklenen performans özellikleri açısından vazgeçilmesi kolay olmayan ürünler arasında olduğu için deri işlenti reçetelerinden bu ürünleri tamamen kaldırmak çok da kolay değildir. Deri işlenti reçetelerinden bu ürünleri tamamen kaldırmak yerine, alternatif bazı yöntemlerle bu ürünlerin dezavantajlarını elimine etme çalışmaları son yıllarda deri sanayi açısından üzerinde durulan önemli hususlardandır. 100 ppm'in üzerinde formaldehit içeren deri ürünleri üzerinde yapılan bir araștırmada fenolik bileșenler ile mevcut değer 60 ppm'lere [16], yaklaşık 50 ppm formaldehit içeren deri ürünlerinde ise antioksidan bileşenler ile 25 ppm düzeylerine düşürülebilmiştir [13]. Tara ve fosfonyum kombine tabaklama yöntemi ile iyi kalitede derilerin elde edildigi, tara'nın iyi bir formaldehit önleyici olduğu, ayrıca krom olmadan yapılan bu tabaklama yöntemi ile $\mathrm{Cr}(\mathrm{VI})$ oluşumunun da ortadan kaldırıldığı vurgulanmıştır [28]. Bir başka araştırmada deri sanayi traş atıkları formaldehit önleyici olarak kullanılmış, bu sayede sanayinin atık yükünün de azalacağı belirtilmiştir [29]. Tüm bu öneriler dikkate alınarak üretim yapıldığında mamul ürünlerde zararlı içeriklere ilişkin sıkıntılar minimuma inecektir. Böylece ihracatta karşılaşılan engeller ortadan kalkacak, deri sanayi çevreye duyarlı üretimi ile ön plana çıkacak ve ülke ekonomisine katkıda bulunmaya devam edecektir.

\section{Teşekkür}

Deri ürünlerinin temini konusunda verdiği destekten dolayı Ata Dilek Deri ve Otomotiv San. \& Tic. A.Ş’ye, ayrıca bazı analizler konusunda verdiği destek için Kazlıçeşme Ar-Ge Merkezi ve Test Laboratuvarlarına teşekkür ederiz. 


\section{Kaynakça}

[1] Özçörekçi M, Öngüt E. 2005. Dünyada ve Türkiye'de Deri ve Deri Ürünleri Sanayiinin Gelișme Eğilimleri ve Geleceği. DPT (T.C. Başbakanlık Devlet Planlama Teșkilatı), İktisadi Sektörler ve Koordinasyon Genel Müdürlüğü, 335s.

[2] Çelebi H, Kara EE. 2007. Niğde İli Bor İlçesi Tabakhanelerinden Çı⿰亻⿱丶⿻工二木 Atıksuların Tarım Topraklarının Kirliliğine Olan Etkisinin Araştırılması. Uluslararası Küresel İklim Değișikliği ve Çevresel Etkileri Konferansı, 18-20 Ekim, Konya, 379-383.

[3] Çolak SM. 2015. Hazardous Chemicals Used in Leather Production and Effects on Human Health. 3rd International Leather Engineering Congress, Innovative Aspects for Leather Industry, 21-22 Mayıs, İzmir, 295-305.

[4] Sojka-Ledakowicz J, Olczyk J, Polak J, Graz M, Jarosz-Wilkolazka A. 2015. Dyeing of Textile Fabrics with Bio-Dyes, Fibres and Textiles in Eastern Europe, Cilt. 23, s. 120125.

[5] Lee SC, Shin EC, Kim WJ. 2014. Dyeing Properties of Natural Leather Using Red Natural Dyes, Journal of the Society of Leather Technologists and Chemists, Cilt. 98, s. 252-258.

[6] Dave H, Ledwani L, Nema SK. 2016. Surface Modification by Atmospheric Pressure Air Plasma Treatment to Improve Dyeing with Natural Dyes: An Environment Friendly Approach for Leather Processing, Plasma Chemistry and Plasma Processing, Cilt. 36, s. 599613. DOI: $10.1007 / \mathrm{s} 11090-015-$ 9687-9

[7] Velmurugan P, Shim J, Seo SK, Oh BT. 2016. Extraction of Natural Dye from Coreopsis tinctoria Flower
Petals for Leather Dyeing - An Ecofriendly Approach, Fibers and Polymers, Cilt. 17, s. 1875-1883. DOI: $10.1007 / \mathrm{s} 12221-016-6226-0$

[8] Kanagaraj J, Senthilvelan T, Panda RC, Kavitha S. 2015a. Eco-Friendly Waste Management Strategies for Greener Environment Towards Sustainable Development in Leather Industry: A Comprehensive Review, Journal of Cleaner Production, Cilt. 89, s. 1-17. DOI: 10.1016/j.jclepro.2014.11.013

[9] Kanagaraj J, Senthilvelan T, Panda RC. 2015b. Degradation of Azo Dyes by Laccase: Biological Method to Reduce Pollution Load in Dye Wastewater, Clean Technologies and Environmental Policy, Cilt. 17, s. 1443-1456. DOI: 10.1007/s10098-014-0869-6

[10] Herva M, Alvarez A, Roca E. 2011. Sustainable and Safe Design of Footwear Integrating Ecological Footprint and Risk Criteria, Journal of Hazardous Materials, Cilt. 192, s. 1876-1881.

DOI: 10.1016/j.jhazmat.2011.07.028

[11] Covington AD. 2009. Tanning Chemistry, The Science of Leather. The University of Northampton, Northampton, UK, 520s.

[12] Bayramoglu EE, Onem E, Yorgancioglu A. 2012. Reduction of Hexavalent Chromium Formation in Leather with Various Natural Products (Coridothymus capitatus, Olea europaea, Corylus avellana, and Juglans regia), Ekoloji, Cilt. 21, s. 114-120. DOI: 10.5053/ekoloji.2011.8413

[13] Colak SM, Dandar U, Kilic E. 2014. Antioxidant Effect of Tannic Acid on Formation of Formaldehyde and Hexavalent Chromium Compounds in Leather, Tekstil ve Konfeksiyon, Cilt. 24, s. 105-110.

[14] Ozgunay H, Yilmaz O, Dandar U, Colak S, Zengin G, Afsar A, Simion 
E. Önem vd. / Deri Sanayinde İhracatı Tehdit Eden Yasaklı Maddelerin Ayakkabılık Mamul Derilerde Araştırılması

D, Gaidau C. 2016. The Effect of Valonea and Henna Treatment and Post-Mordanting on $\mathrm{Cr}$ (VI) and Free Formaldehyde Formation in Leather, Tekstil ve Konfeksiyon, Cilt. 26, s. 327-334.

[15] Yilmaz B, Onem E, Yorgancioglu A, Bayramoglu EE. 2016. UV Protection Against Photoageing of Garment Leathers by ZnO Nanoparticles: Application of Nano $\mathrm{ZnO}$ in Finishing Process as Photocatalyst, Journal of the Society of Leather Technologists and Chemists, Cilt. 100, s. 321-326.

[16] Bayramoglu EE, Onem E, Yorgancioglu A. 2013. Analysis of Release of Free Formaldehyde Originated from THP Salt Tannages in Leather by High Performance Liquid Chromatography: Origanum onites Essential Oil as Free Formaldehyde Scavenger, Journal of the American Leather Chemists Association, Cilt. 108, s. 411-419.

[17] Zhang SX, Chai XS, Huang BX, Mai XX. 2015. A Robust Method for Determining Water-Extractable Alkylphenol Polyethoxylates in Textile Products by Reaction-Based Headspace Gas Chromatography, Journal of Chromatography A, Cilt. 1406, s. 94-98. DOI: 10.1016/j.chroma.2015.06.001

[18] Van Mourik LM, Leonards PEG, Gaus C, De Boer J. 2015. Recent Developments in Capabilities for Analysing Chlorinated Paraffins in Environmental Matrices: A review, Chemosphere, Cilt. 136, s. 259-272. DOI:

10.1016/j.chemosphere.2015.05.0 45

[19] Rey A, Blanc N, Cannot JC, Berthod A. 2011. Determination of Short Polychlorinated Alkanes in Leather Using Gas ChromatographyElectron Capture Negative Chemical Ionization Mass Spectrometry, Journal of the
American Leather Chemists Association, Cilt. 106, s. 294-302.

[20] TS EN ISO 17234-1. 2014. Deri Boyalı Derilerde Belirli Azo Boyar Maddelerin Tayini İçin Kimyasal Deneyler - Bölüm 1: Azo Boyar Maddelerden Türetilen Belirli Aromatik Aminlerin Tayini. Türk Standartları Enstitüsü, 21s, Ankara.

[21] TS EN 14372. Deri - Kimyasal Deneyler - Fitalat Tayini.

[22] TS EN ISO 17226-1. 2009. Deri Fomaldehit İçeriğinin Kimyasal Tayini - Bölüm 1: Yüksek Performans Sıvı Kromotografik Yöntem. Türk Standartları Enstitüsü, 17s, Ankara.

[23] TS EN ISO 17075. 2008. Deri Kimyasal Deneyler - Krom 6 Tayini. Türk Standartları Enstitüsü, 19s, Ankara.

[24] American Apparel \& Footwear Association (AAFA), 2016. Restricted Substances List (RSL), April, Seventeenth Edition.

[25] Bennett J, Miah YA, Varsani DS, Salvadori E, Sheriff TS. 2016. Selective Oxidative Degradation of Azo Dyes by Hydrogen Peroxide Catalysed by Manganase(II) Ions, RSC Advances, Cilt. 6, s. 103372 103381. DOI: $10.1039 / c 6 r a 23067 a$

[26] Aslan A. 2009. Determination of Heavy Metal Toxicity of Finished Leather Solid Waste, Bulletin of Environmental Contamination and Toxicology, Cilt. 82, s. 633-638. DOI: $10.1007 / \mathrm{s} 00128-009-9656-1$

[27] Karavana HA, Basaran B, Aslan A, Bitlisli BO, Gulumser G. 2011. Heavy Metal Contents of Bootee Leathers Tanned with Different Process Recipes, Tekstil ve Konfeksiyon, Cilt. 21, s. 305-310.

[28] Aravindhan R, Madhan B, Rao JR. 2011. Studies on TaraPhosphonium Combination Tannage: Approach Towards A Metal Free Eco-Benign Tanning System, Journal of the American 
E. Önem vd. / Deri Sanayinde İhracatı Tehdit Eden Yasaklı Maddelerin Ayakkabılık Mamul Derilerde Araştırılması

Leather Chemists Association, Cilt.

110, s. 80-87.

[29] Wang XC, Ren LF, Qiang TT. 2009.

Novel Way of Transformation of

Tannery Waste to Environmentally

Friendly Formaldehyde Scavenger,

Environmental Progress \&

Sustainable Energy, Cilt. 28, s. 285-

290. DOI: $10.1002 /$ ep.10329 